\title{
Midregional pro atrial natriuretic peptide: a novel important biomarker for noise annoyance-induced cardiovascular morbidity and mortality?
}

\author{
Omar Hahad ${ }^{1,2}$. Philipp S. Wild ${ }^{2,3,4}$. Jürgen H. Prochaska ${ }^{2,3,4} \cdot$ Andreas Schulz $^{3} \cdot$ Karl J. Lackner $^{2,5} \cdot$ Norbert Pfeiffer $^{6}$. \\ Irene Schmidtmann ${ }^{7} \cdot$ Matthias Michal $^{2,8} \cdot$ Manfred Beutel $^{8} \cdot$ Andreas Daiber $^{1,2} \cdot$ Thomas Münzel $^{1,2,4}$
}

Received: 11 February 2020 / Accepted: 6 April 2020 / Published online: 18 April 2020

(c) The Author(s) 2020

\begin{abstract}
Background Environmental noise exposure has been associated with increased cardiovascular morbidity and mortality. Recently, noise annoyance was shown to induce atrial fibrillation, which was accompanied by significantly increased levels of midregional pro atrial natriuretic peptide (MR-proANP). Therefore, the aim of the present study was to analyze the association between noise annoyance, MR-proANP, incident cardiovascular events, and all-cause mortality.

Methods Levels of MR-proANP were measured in the first 5000 participants of the population-based Gutenberg Health Study. Annoyance was assessed separately for aircraft, road traffic, railway, neighborhood, and industrial/construction noise during the day and sleep.

Results In cross-sectional analyses, aircraft noise annoyance during day and sleep, industrial/construction noise annoyance during day, and railway noise annoyance during sleep were independently associated with increased levels of MR-proANP after multivariable adjustment. After a 5-year follow-up period, there were 43 cases of incident atrial fibrillation and 103 of incident cardiovascular disease (comprising atrial fibrillation, coronary artery disease, myocardial infarction, heart failure, or stroke). Moreover, there were 301 deaths after a mean follow-up of $7.42 \pm 1.66$ years. An odds ratio (OR) of 2.82 ([95\% confidence interval (CI) 1.86; 4.35], $p<0.0001$ ) for incident atrial fibrillation and an OR of 1.49 ([95\% CI 1.13; 1.96], $p=0.0046$ ) for incident cardiovascular disease per 1-standard deviation (SD) increase in MR-proANP levels were found. A $36 \%$ (hazard ratio: 1.36 [95\% CI 1.19; 1.55], $p<0.0001$ ) higher risk of death was found per 1-SD increase in MR-proANP levels.
\end{abstract}

Thomas Münzel

tmuenzel@uni-mainz.de

1 Center for Cardiology-Cardiology I, University Medical Center of the Johannes Gutenberg-University Mainz, Langenbeckstraße 1, 55131 Mainz, Germany

2 German Center for Cardiovascular Research (DZHK), Partner site Rhine-Main, Mainz, Germany

3 Preventive Cardiology and Preventive Medicine, Center for Cardiology, University Medical Center of the Johannes Gutenberg-University Mainz, Mainz, Germany

4 Center for Thrombosis and Hemostasis, University Medical Center of the Johannes Gutenberg-University Mainz, Mainz, Germany
5 Institute of Clinical Chemistry and Laboratory Medicine, University Medical Center of the Johannes Gutenberg-University Mainz, Mainz, Germany

6 Department of Ophthalmology, University Medical Center of the Johannes Gutenberg-University Mainz, Mainz, Germany

7 Institute of Medical Biostatistics, Epidemiology and Informatics, University Medical Center of the Johannes Gutenberg-University Mainz, Mainz, Germany

8 Department of Psychosomatic Medicine and Psychotherapy, University Medical Center of the Johannes Gutenberg-University Mainz, Mainz, Germany 
Conclusions Noise annoyance may contribute to cardiovascular morbidity and mortality and is characterized by increased levels of MR-proANP.

\section{Graphic abstract}

\section{What is known...}

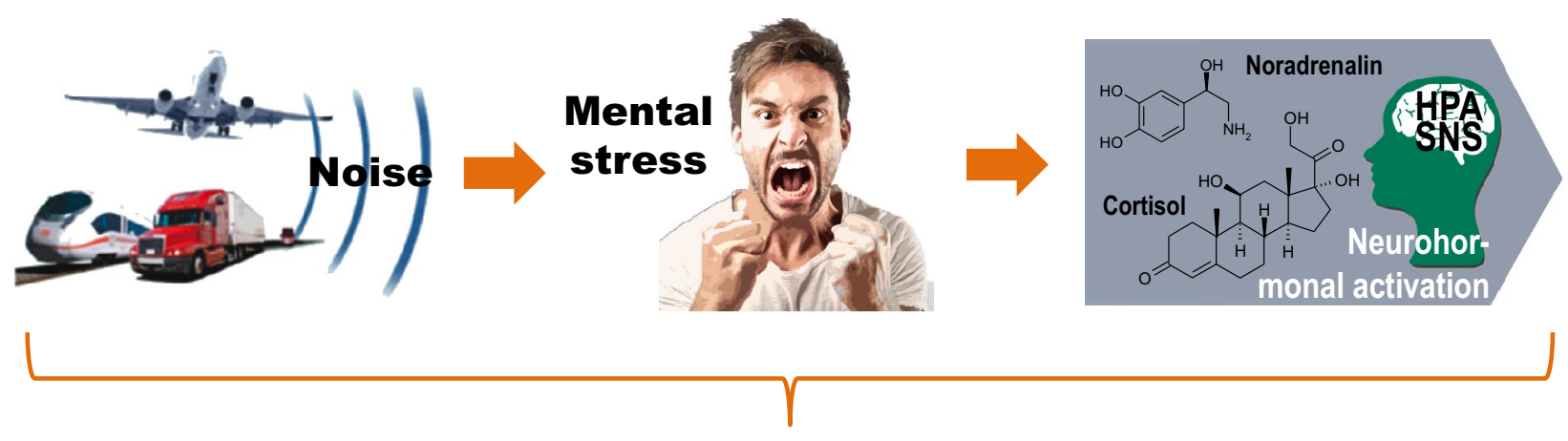

\section{What is new...}

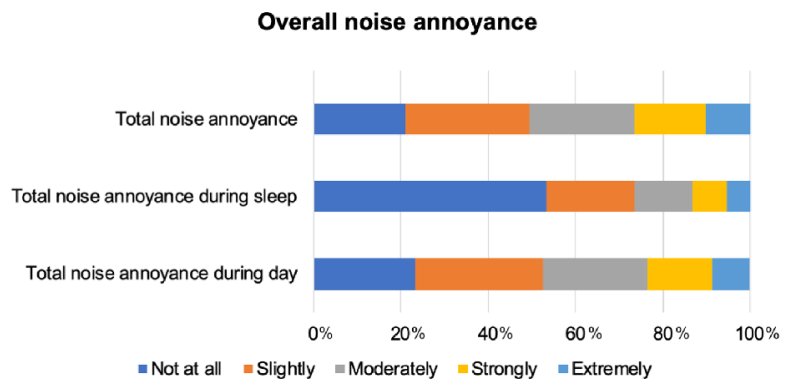

Keywords Noise annoyance $\cdot$ Risk factor $\cdot$ Midregional pro atrial natriuretic peptide $\cdot$ Cardiovascular disease $\cdot$ Mortality

\section{Introduction}

Environmental noise exposure is a well-established risk factor for cardiovascular disease [1]. Over the past decade, several high-quality studies support that traffic noise exposure, the most significant source of noise pollution in Europe, is associated with increased risk of arterial hypertension, ischemic heart disease, stroke, and myocardial infarction $[2,3]$. Babisch's noise reaction model and the non-auditory pathway are regarded as the central framework by which noise induces adverse health effects $[4,5]$. In this context, noise can negatively affect communication, daily activities,

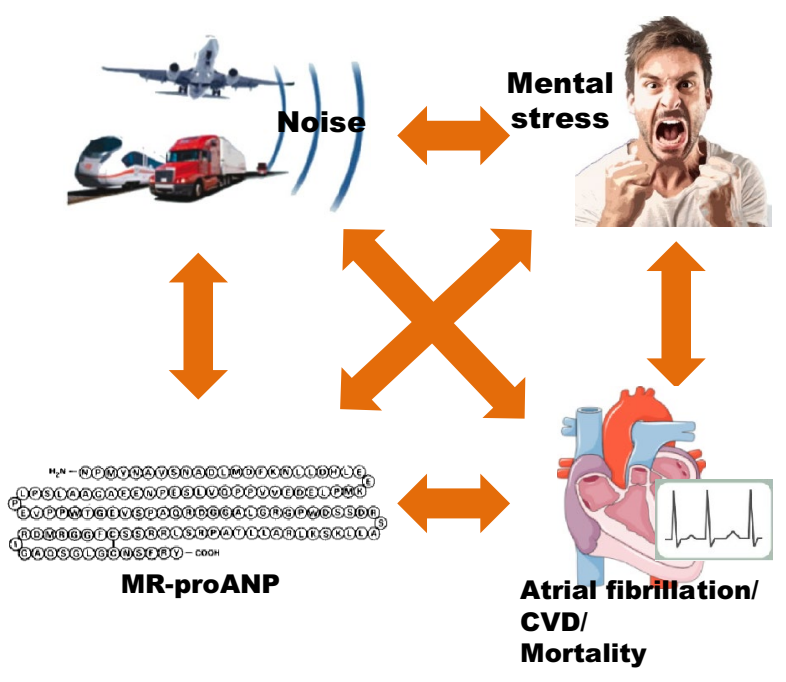

and sleep, leading to annoyance, mental stress, and subsequent sympathetic and endocrine activation [2, 6, 7]. If the exposure becomes chronic, noise initiates a pathophysiological cascade, resulting in increased stress hormone levels, blood pressure, and heart rate, which in turn promotes the manifestation of cardiovascular risk factors and diseases [8]. However, mechanistic insight by which noise triggers detrimental effects on the cardiovascular system is still elusive. Recent human studies suggest that traffic noise exposure causes the release of stress hormones and inflammatory signaling molecules leading to oxidative stress and subsequent endothelial dysfunction and arterial stiffening [9-12]. We have also demonstrated that noise annoyance is associated with a higher risk of prevalent atrial fibrillation, which was further accompanied by an increased trend of midregional pro atrial natriuretic peptide (MR-proANP) plasma levels [13]. Midregional pro atrial natriuretic peptide 
mirrors vascular (endothelial) activation and has been correlated with endothelial dysfunction in humans including flowmediated vasodilation and markers of peripheral arterial tonometry [14]. Furthermore, assessment of MR-proANP has been shown to be useful in patients with prevalent cardiovascular disease as an indicator of cardiovascular risk and mortality in initially healthy subjects [15]. Therefore, the present study aimed to investigate the relationship between noise annoyance, levels of MR-proANP, incident cardiovascular events, and mortality in the large population-based Gutenberg Health Study (GHS).

\section{Methods}

\section{Study design and sample}

The analysis was based on data from the GHS, a populationbased, prospective, observational single-center cohort study from Mid-Western Germany [16]. The sample was drawn randomly from the local registry in the city of Mainz and the district of Mainz-Bingen. Insufficient knowledge of German language, psychological, or physical impairment hindering participation in the study led to exclusion. The GHS puts main emphasis on cardiovascular risk stratification, as well as focus on metabolic, ophthalmological, cancer, immune system, and mental diseases. The age-, sex-, and residencestratified study sample included 15,010 individuals (age range 35-74 years) of the baseline examination performed from April 2007 to April 2012 at the University Medical Center Mainz, Germany. Assessment of MR-proANP was conducted in the first 5000 individuals, thus analyses were restricted to this subpopulation. In a standardized 5-h-long baseline-examination, individuals underwent a variety of interviews and clinical examinations with comprehensive assessment of lifestyle, psychosocial, environmental, and laboratory parameters according to standard operating procedures. Follow-up examinations were performed 5 years after enrollment, i.e. from 2012 to 2017. The GHS and its study procedures were approved by the ethics committee of the Statutory Physician Board of the State RhinelandPalatinate [Reference No. 837.020.07(5555)] and the local data safety commissioners. The study design was in line with the tenets of the revised Helsinki protocol and principles outlined in recommendations for Good Clinical and Epidemiological Practice. Written informed consent was obtained from all individuals prior to participation.

\section{Noise annoyance}

Noise annoyance was assessed in accordance to previous protocols published by Felscher-Suhr, Guski and Schluemer [17]. Participants were asked to rate "how annoyed have you been in the past years by..." using a 5-point Likert scale ranging from "not at all", over "slightly", "moderately", and "strongly" to "extremely". Multiple sources of annoyance including road traffic, aircraft, railway, industrial/construction, and neighborhood noise "during the day" and "in your sleep" were assessed.

\section{Measures}

Venous blood was obtained after an overnight fast (at least $8 \mathrm{~h}$ ) and samples were processed for plasma and stored in aliquots at $-80{ }^{\circ} \mathrm{C}$ immediately after blood draw. Routine laboratory methods were used for blood glucose and lipid measurements. In brief, MR-proANP was determined using a commercial available assay (immunoluminometric assay MR-proANP, Brahms GmbH, Hennigsdorf/Berlin, Germany) according to the manufacturer's instructions as reported previously [14]. Reproducibility was good, with all of the coefficients of variation (intra-assay and interassay) $<5 \%$. Medication history was derived from medical records and was categorized according to the Anatomical Therapeutic Chemical Classification System [18].

Further variables were defined as follows: arterial hypertension was defined as systolic blood pressure $\geq 140 \mathrm{mmHg}$ or diastolic blood pressure $\geq 90 \mathrm{mmHg}$ at rest (mean of $2 \mathrm{nd}$ and 3rd standardized measurement after 8 and $11 \mathrm{~min}$ of rest), or by intake of any antihypertensive drugs within the last 2 weeks, or arterial hypertension diagnosed by a physician. Diabetes mellitus was defined by already diagnosed or a fasting blood glucose level (overnight fast of at least $8 \mathrm{~h}) \geq 126 \mathrm{mg} / \mathrm{dL}$ or $\mathrm{HbA} 1 \mathrm{c}>6.5 \%$, or a non-fasting blood glucose level (less than $8 \mathrm{~h}$ of fasting) $\geq 200 \mathrm{mg} / \mathrm{dL}$. Also, subjects with intake of oral blood glucose-lowering drugs or receiving insulin therapy were classified as diabetic. Dyslipidemia was defined as at least one of the following: physician diagnosis of dyslipidemia, low-density lipoprotein cholesterol/high-density lipoprotein cholesterol ratio $>3.5$, or triglycerides $\geq 150 \mathrm{mg} / \mathrm{dL}$. A positive family history of myocardial infarction or stroke was recorded in a female first-degree relative $\leq 65$ years or in a male first-degree relative $\leq 60$ years. Never and former smokers were defined as non-smokers and current smokers as smokers. Body mass index was used for the definition of obesity following the World Health Organization (WHO) criteria [19]. Family history of myocardial infarction or stroke was self-reported. Incident cardiovascular disease was assessed on the basis of medical history or diagnosis during a standardized interview as any of the following: atrial fibrillation, coronary artery disease, myocardial infarction, heart failure, or stroke.

Mortality updates were performed by quarterly queries to the registry offices and the mortality registry RhinelandPalatinate. For death reviews, official death certificates were acquired. Socioeconomic status was assessed by a validated 
index score comprising information about educational background, current occupation, and income (ranging from 3 to 21) with a higher score indicating higher socioeconomic status [20]. Night shift work was considered as current or noncurrent. Further details on measurements have been reported previously $[21,22]$.

\section{Statistical analysis}

Baseline characteristics are shown according to total noise annoyance as absolute and relative frequency for categorical variables and as mean value and standard deviation (SD) or median with 25 th and 75 th percentiles for continuous variables. Statistical comparisons for categorical variables were made by Fisher exact or $\chi^{2}$ tests and for continuous variables Mann-Whitney $U$ or Student $t$ tests were used, respectively. Total noise annoyance was defined as highest annoyance rating regardless of the specific noise source and of whether it affected daytime or sleep. Linear regression analysis with corresponding beta estimates $(\beta)$ were used to assess the association between noise annoyance and levels of MR-proANP. Odds ratios (OR) from a logistic regression model were used to analyze the impact of MR-proANP on incident cardiovascular events. For analyses of all-cause mortality, Cox proportional hazard regression models with corresponding hazard ratios (HR) were used. All regression models were adjusted sequentially. Because of the explorative nature of the study, no Bonferroni correction of $p$ values was conducted. $p$ values should be treated as a continuous measure of statistical strength of an association and they are therefore reported exactly. All tests were two-sided and $p$ values $<0.05$ were considered significant. The statistical data analyses were performed using the software R, version 3.5.1 (https:// www.r-project.org/).

\section{Results}

\section{Baseline characteristics}

A total of 4826 subjects answered the questions about noise annoyance. Baseline characteristics of this study sample stratified by the degree of total noise annoyance are displayed in Table 1 . Nearly $80 \%$ of the subjects reported being affected by noise annoyance to a certain degree (not at all: $21.1 \%$, slightly: $28.4 \%$, moderately: $24.0 \%$, strongly: $16.2 \%$, extremely: $10.3 \%$ ). Extremely annoyed subjects were more likely to be women (54.2\%), had the highest prevalence of current smoking $(23.0 \%)$, and highest use of antihypertensives $(1.6 \%)$ and diuretics $(6.7 \%)$. Midregional pro atrial natriuretic peptide levels tended to increase from no to extreme annoyance (65.7 to $69.0 \mathrm{pmol} / \mathrm{L})$. No clear trend was observed in the case of other sociodemographic variables, cardiovascular risk factors, and medication use.

\section{Noise annoyance}

As evident in Fig. 1, aircraft noise was the leading source of annoyance in the population affecting nearly $60 \%$ during day and more than $30 \%$ during sleep. Moreover, aircraft noise was the leading source of strong and extreme annoyance (day: $14.4 \%$, sleep: $8.9 \%$ ). This was followed by road traffic (day: $41.1 \%$, sleep: $17.2 \%$ ), neighborhood (day: $34.2 \%$, sleep: $15.6 \%$ ), railway (day: $15.7 \%$, sleep: $9.0 \%$ ), and industrial/construction (day: $12.5 \%$, sleep: $3.1 \%$ ) noise annoyance. Overall, total noise annoyance was higher during the day than sleep, affecting $76.6 \%$ during the day and $46.8 \%$ during sleep.

\section{Association between noise annoyance and MR-proANP}

Aircraft noise annoyance during day $(\beta$ : 0.016 [95\% CI $0.0070 ; 0.025], p=0.00049$ per point increase in annoyance) as well as during sleep ( $\beta$ : 0.020 [95\% CI 0.010; 0.030], $p<0.0001$ ) was independently associated with increased levels of MR-proANP after multivariable adjustment for sex, age, socioeconomic status, length of time at current residence, night shift work, diabetes mellitus, arterial hypertension, current smoking, obesity, dyslipidemia, family history of myocardial infarction or stroke, and medication use (Table 2). Moreover Industrial/construction noise annoyance during day $(\beta$ : 0.019 [95\% CI $0.0021 ; 0.036], p<0.028)$ and railway noise annoyance during sleep $(\beta: 0.028$ [95\% CI $0.0075 ; 0.049$ ], $p=0.0078$ ) were independently associated with increased MR-proANP levels. Furthermore, total noise annoyance $(\beta: 0.013$ [95\% CI $0.0041 ; 0.021], p=0.0036)$ as well as total noise annoyance during day $(\beta$ : $0.014[95 \%$ CI $0.0057 ; 0.023], p=0.0012)$ and sleep $(\beta: 0.011$ [95\% CI $0.0019 ; 0.020], p=0.017)$ were independently associated with higher levels of MR-proANP.

\section{Impact of MR-proANP on incident cardiovascular events and all-cause mortality}

In the next step, impact of MR-proANP on incident atrial fibrillation as well as on incident cardiovascular disease (composite variable comprising incident atrial fibrillation, coronary artery disease, myocardial infarction, heart failure, or stroke; Table 3) and all-cause mortality (Table 4) was evaluated. During the 5-year follow-up period, incident atrial fibrillation and incident cardiovascular disease occurred in $n=43$ and $n=103$ subjects, respectively. There were 301 deaths after a mean 
Table 1 Baseline characteristics of the study sample by degree total noise annoyance $(n=4826)$

\begin{tabular}{|c|c|c|c|c|c|c|}
\hline Variable & Not at all $(n=1018)$ & Slightly $(n=1372)$ & Moderately $(n=1160)$ & Strongly $(n=780)$ & Extremely $(n=496)$ & $p$ value \\
\hline Female sex, no. $(\%)$ & $529(52.0)$ & $631(46.0)$ & $561(48.4)$ & $378(48.5)$ & $269(54.2)$ & 0.016 \\
\hline Age, years & $56.8 \pm 10.7$ & $54.2 \pm 10.7$ & $55.6 \pm 11.2$ & $54.5 \pm 11.1$ & $55.5 \pm 10.8$ & 0.65 \\
\hline Socioeconomic status & $11.99 \pm 4.38$ & $13.19 \pm 4.42$ & $12.67 \pm 4.34$ & $12.90 \pm 4.49$ & $12.40 \pm 4.41$ & 0.13 \\
\hline $\begin{array}{l}\text { Time at current residence, } \\
\text { years }\end{array}$ & $20.65 \pm 15.40$ & $19.26 \pm 14.65$ & $20.80 \pm 15.44$ & $19.80 \pm 14.92$ & $19.46 \pm 15.21$ & 0.38 \\
\hline Night shift work, no. (\%) & $251(24.7)$ & $349(25.4)$ & $301(25.9)$ & $233(29.9)$ & $131(26.4)$ & 0.91 \\
\hline \multicolumn{7}{|l|}{ Cardiovascular risk factors } \\
\hline MR-proANP (pmol/L) & $65.7(49.9 / 89.5)$ & $63.6(47.7 / 85.4)$ & $67.2(50.0 / 89.8)$ & $65.0(48.0 / 90.9)$ & $69.0(51.0 / 96.0)$ & 0.013 \\
\hline $\begin{array}{l}\text { Diabetes mellitus, no. } \\
(\%)\end{array}$ & $119(11.7)$ & $110(8.1)$ & $109(9.5)$ & $77(9.9)$ & $45(9.1)$ & 0.81 \\
\hline Hypertension, no. (\%) & $534(52.5)$ & $684(49.9)$ & $605(52.2)$ & $382(49.0)$ & $246(49.6)$ & 0.60 \\
\hline $\begin{array}{l}\text { Current smoking, no. } \\
(\%)\end{array}$ & $205(20.1)$ & $247(18.0)$ & $227(19.6)$ & $141(18.1)$ & $114(23.0)$ & 0.036 \\
\hline Obesity, no. (\%) & $292(28.7)$ & $293(21.4)$ & $273(23.5)$ & $182(23.3)$ & $108(21.8)$ & 0.29 \\
\hline Dyslipidemia, no. (\%) & $479(47.1)$ & $581(42.3)$ & $527(45.5)$ & $339(43.6)$ & $230(46.5)$ & 0.42 \\
\hline $\begin{array}{l}\text { Family history of myo- } \\
\text { cardial infarction or } \\
\text { stroke, no. }(\%)\end{array}$ & $242(23.8)$ & $315(23.0)$ & $270(23.3)$ & $170(21.8)$ & $118(23.8)$ & 0.69 \\
\hline \multicolumn{7}{|l|}{ Medication, no. (\%) } \\
\hline $\begin{array}{l}\text { Antidiabetic medication } \\
\text { (A10) }\end{array}$ & $71(7.0)$ & $63(4.6)$ & $68(5.9)$ & $53(6.8)$ & $31(6.3)$ & 0.76 \\
\hline $\begin{array}{l}\text { Antithrombotic agents } \\
\text { (B01) }\end{array}$ & $139(13.7)$ & $137(10.0)$ & $163(14.1)$ & $91(11.7)$ & $64(13.0)$ & 0.66 \\
\hline Antihypertensives (C02) & $13(1.3)$ & $11(0.8)$ & $7(0.6)$ & $9(1.2)$ & $8(1.6)$ & 0.15 \\
\hline Diuretics (C03) & $64(6.3)$ & $57(4.2)$ & $73(6.3)$ & $49(6.3)$ & $33(6.7)$ & 0.36 \\
\hline Beta-blockers (C07) & $174(17.1)$ & $216(15.8)$ & $196(16.9)$ & $113(14.5)$ & $78(15.8)$ & 0.90 \\
\hline $\begin{array}{l}\text { Calcium channel blocker } \\
\text { (C08) }\end{array}$ & $86(8.5)$ & $80(5.9)$ & $80(6.9)$ & $58(7.4)$ & $40(8.1)$ & 0.41 \\
\hline $\begin{array}{l}\text { Agents acting on the } \\
\text { renin-angiotensin- } \\
\text { aldosterone system } \\
\text { (C09) }\end{array}$ & $249(24.5)$ & $278(20.3)$ & $276(23.8)$ & $175(22.5)$ & $116(23.5)$ & 0.69 \\
\hline $\begin{array}{l}\text { Lipid modifying agents } \\
\text { (C10) }\end{array}$ & $160(15.8)$ & $153(11.2)$ & $150(12.9)$ & $103(13.2)$ & $66(13.4)$ & 0.89 \\
\hline
\end{tabular}

Statistically significant $p$ values (i.e. $<0.05)$ are given in bold font

Plus-minus values are means \pm standard deviations and two values in parentheses are medians with 25 th and 75 th percentiles. $P$ value for the comparison of extreme annoyance vs rest. Medication is labeled with the anatomical therapeutic chemical-code

follow-up of $7.42 \pm 1.66$ years. After multivariable adjustment, an OR of 2.82 ([95\% CI 1.86; 4.35], $p<0.0001)$ for incident atrial fibrillation and an OR of 1.49 ([95\% CI 1.13; 1.96], $p=0.0046$ ) for incident cardiovascular disease per 1-SD increase in MR-proANP levels were found. In addition, a 36\% (HR 1.36 [95\% CI 1.19; 1.55], $p<0.0001$ ) higher risk of death was found per 1-SD increase in MR-proANP levels.

\section{Discussion}

To our knowledge, this is the first study that investigated a close association between noise annoyance and levels of MR-proANP, a marker that reflects vascular endothelial activation and predicts future cardiovascular events in the large cohort of the GHS. We established that aircraft noise annoyance during the day and sleep, industrial/construction noise annoyance during the day, and railway noise annoyance during sleep were independently associated with increased levels of MR-proANP even after multivariable adjustment for sociodemographic variables, cardiovascular risk factors, and medication use. Total noise annoyance, as an indicator of overall annoyance regardless of the specific noise source and whether it affected daytime or sleep, was also independently predictive of MR-proANP, as it was the case for total noise annoyance during day and sleep. Moreover, higher levels of MRproANP were shown to be associated with an increased 
Fig. 1 Degrees of noise annoyance during (a) day and (b) sleep according to different sources of noise and (c) overall (a) Noise annoyance during day

Industrial/construction

Neighbourhood

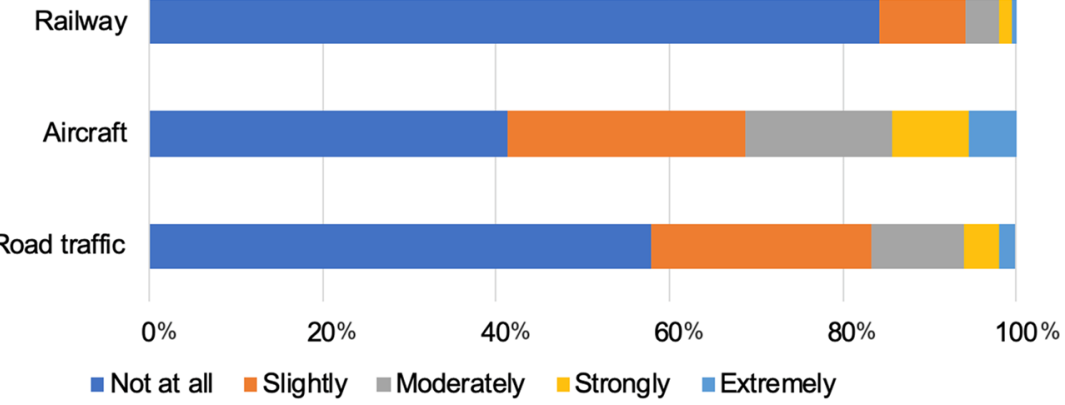

(b)

Noise annoyance during sleep

Industrial/construction

Neighbourhood

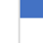
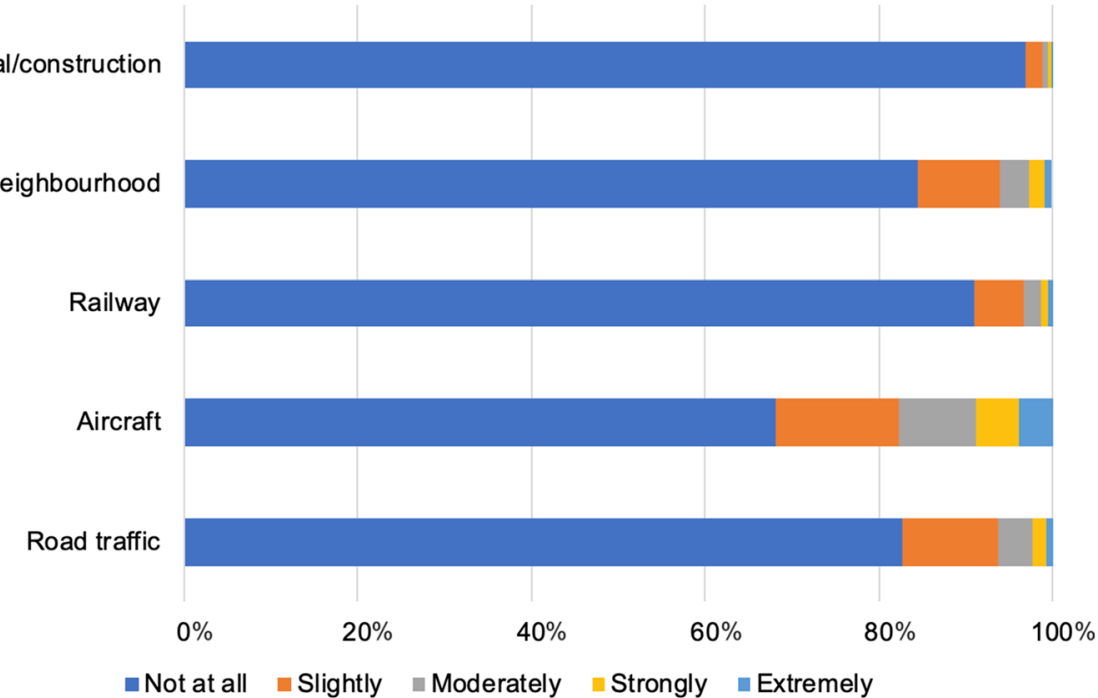

(c)

\section{Overall noise annoyance}

Total noise annoyance

Total noise annoyance during sleep

Total noise annoyance during day

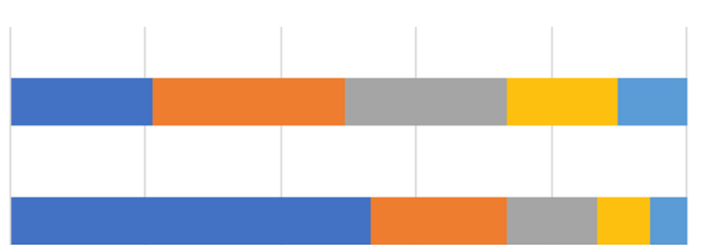

घot at all $\square$ Slightly $\square$ Moderately $\square$ Strongly $\square$ Extremely 
Table 2 Cross-sectional association between noise annoyance and levels of MR-proANP

\begin{tabular}{|c|c|c|c|c|c|c|c|}
\hline \multirow[t]{2}{*}{ Noise annoyance } & \multirow[t]{2}{*}{$n$} & \multicolumn{2}{|l|}{ Model 1} & \multicolumn{2}{|l|}{ Model 2} & \multicolumn{2}{|l|}{ Model 3} \\
\hline & & $\begin{array}{l}\text { Beta estimate per } \\
\text { point increase }[95 \% \\
\mathrm{CI}]\end{array}$ & $p$ value & $\begin{array}{l}\text { Beta estimate per } \\
\text { point increase }[95 \% \\
\text { CI] }\end{array}$ & $P$ value & $\begin{array}{l}\text { Beta estimate per } \\
\text { point increase }[95 \% \\
\mathrm{CI}]\end{array}$ & $p$ value \\
\hline \multicolumn{8}{|l|}{ During day } \\
\hline Road traffic & 4,766 & $\begin{array}{l}0.0037 \\
{[-0.0085 ; 0.016]}\end{array}$ & 0.55 & $\begin{array}{l}0.0051 \\
{[-0.0072 ; 0.017]}\end{array}$ & 0.41 & $\begin{array}{l}0.0053 \\
{[-0.0061 ; 0.017]}\end{array}$ & 0.36 \\
\hline Aircraft & 4,764 & $\begin{array}{l}0.017 \\
\quad[0.0077 ; 0.027]\end{array}$ & 0.00046 & $\begin{array}{l}0.016 \\
\quad[0.0061 ; 0.026]\end{array}$ & 0.0015 & $\begin{array}{l}0.016 \\
\quad[0.0070 ; 0.025]\end{array}$ & 0.00049 \\
\hline Railway & 4,761 & $\begin{array}{l}0.016 \\
\quad[-0.0019 ; 0.034]\end{array}$ & 0.080 & $\begin{array}{l}0.018 \\
\quad[-0.000049 ; 0.036]\end{array}$ & 0.051 & $\begin{array}{l}0.013 \\
\quad[-0.0035 ; 0.029]\end{array}$ & 0.12 \\
\hline Neighborhood & 4,764 & $\begin{array}{l}0.013 \\
\quad[-0.000043 ; 0.027]\end{array}$ & 0.051 & $\begin{array}{l}0.016 \\
{[0.0021 ; 0.029]}\end{array}$ & 0.024 & $\begin{array}{l}0.0098 \\
{[-0.0027 ; 0.022]}\end{array}$ & 0.12 \\
\hline Industrial/construction & 4,763 & $\begin{array}{l}0.015 \\
\quad[-0.0034 ; 0.034]\end{array}$ & 0.11 & $\begin{array}{l}0.016 \\
\quad[-0.0025 ; 0.034]\end{array}$ & 0.091 & $\begin{array}{l}0.019 \\
{[0.0021 ; 0.036]}\end{array}$ & 0.028 \\
\hline \multicolumn{8}{|l|}{ During sleep } \\
\hline Road traffic & 4,748 & $\begin{array}{l}0.0086 \\
{[-0.0086 ; 0.026]}\end{array}$ & 0.33 & $\begin{array}{l}0.0100 \\
{[-0.0072 ; 0.027]}\end{array}$ & 0.26 & $\begin{array}{l}0.0081 \\
\quad[-0.0078 ; 0.024]\end{array}$ & 0.32 \\
\hline Aircraft & 4,746 & $\begin{array}{l}0.023 \\
\quad[0.012 ; 0.033]\end{array}$ & $<0.0001$ & $\begin{array}{l}0.021 \\
\quad[0.0098 ; 0.031]\end{array}$ & 0.00018 & $\begin{array}{l}0.020 \\
{[0.010 ; 0.030]}\end{array}$ & $<0.0001$ \\
\hline Railway & 4,746 & $\begin{array}{l}0.032 \\
\quad[0.0097 ; 0.055]\end{array}$ & 0.0051 & $\begin{array}{l}0.033 \\
\quad[0.010 ; 0.055]\end{array}$ & 0.0041 & $\begin{array}{l}0.028 \\
\quad[0.0075 ; 0.049]\end{array}$ & 0.0078 \\
\hline Neighborhood & 4,747 & $\begin{array}{l}-0.0014 \\
{[-0.019 ; 0.016]}\end{array}$ & 0.87 & $\begin{array}{l}0.0012 \\
\quad[-0.016 ; 0.018]\end{array}$ & 0.89 & $\begin{array}{l}0.0014 \\
\quad[-0.015 ; 0.018]\end{array}$ & 0.87 \\
\hline Industrial/construction & 4,744 & $\begin{array}{l}0.018 \\
\quad[-0.019 ; 0.056]\end{array}$ & 0.34 & $\begin{array}{l}0.019 \\
\quad[-0.019 ; 0.056]\end{array}$ & 0.33 & $\begin{array}{l}0.020 \\
\quad[-0.014 ; 0.054]\end{array}$ & 0.25 \\
\hline \multicolumn{8}{|l|}{ Overall } \\
\hline $\begin{array}{l}\text { Total noise annoyance } \\
\text { during day }\end{array}$ & 4,766 & $\begin{array}{l}0.015 \\
\quad[0.0060 ; 0.025]\end{array}$ & 0.0014 & $\begin{array}{l}0.015 \\
\quad[0.0059 ; 0.025]\end{array}$ & 0.0014 & $\begin{array}{l}0.014 \\
\quad[0.0057 ; 0.023]\end{array}$ & 0.0012 \\
\hline $\begin{array}{l}\text { Total noise annoyance } \\
\text { during sleep }\end{array}$ & 4,750 & $\begin{array}{l}0.012 \\
\quad[0.0021 ; 0.021]\end{array}$ & 0.017 & $\begin{array}{l}0.011 \\
\quad[0.0011 ; 0.020]\end{array}$ & 0.029 & $\begin{array}{l}0.011 \\
\quad[0.0019 ; 0.020]\end{array}$ & 0.017 \\
\hline Total noise annoyance & 4,767 & $\begin{array}{l}0.014 \\
\quad[0.0044 ; 0.023]\end{array}$ & 0.0037 & $\begin{array}{l}0.013 \\
\quad[0.0043 ; 0.023]\end{array}$ & 0.0041 & $\begin{array}{l}0.013 \\
\quad[0.0041 ; 0.021]\end{array}$ & 0.0036 \\
\hline
\end{tabular}

Statistically significant $p$ values (i.e. $<0.05)$ are given in bold font

Beta estimates and 95\% confidence intervals are derived from a linear regression model modeling for MR-proANP levels (dependent variable) per point increase in noise annoyance (independent variable). $n$ denotes model 3

Model 1 was adjusted for sex (categorical) and age (continuous)

Model 2 was additionally adjusted for socioeconomic status (continuous), length of time at current residence (continuous), and night shift work (categorical)

Model 3 was additionally adjusted for diabetes mellitus, arterial hypertension, smoking, obesity, dyslipidemia, family history of myocardial infarction or stroke, and medication use (diabetic drugs, antithrombotic agents, antihypertensives, diuretics, beta-blockers, calcium channel blocker, agents acting on the renin-angiotensin-aldosterone system, and lipid modifying agents) (all categorical)

risk of incident atrial fibrillation and future cardiovascular disease. Likewise, the risk of death was associated with higher MR-proANP levels. Importantly, these associations were only marginally influenced by stepwise adjustment for confounders, implicating that noise annoyance may constitute an independent risk factor via association with MR-proANP. These findings suggest that noise annoyance may contribute to increased morbidity and mortality and is characterized by increased levels of MR-proANP.

\section{Noise annoyance in the population-the importance of aircraft noise}

Traffic noise, which is steadily increasing due to increasing demand for transportation and growing urbanization, is the major source of noise annoyance in Western European countries. The WHO estimates that traffic-related noise exposure is responsible for a yearly loss of up to 1.6 million years of healthy life in Western Europe, mainly due to 
Table 3 Association between levels of MR-proANP and incident atrial fibrillation or cardiovascular disease

\begin{tabular}{|c|c|c|c|c|c|c|c|}
\hline & \multirow[t]{2}{*}{$n$} & \multicolumn{2}{|l|}{ Model 1} & \multicolumn{2}{|l|}{ Model 2} & \multicolumn{2}{|l|}{ Model 3} \\
\hline & & Odds ratio per SD $[95 \% \mathrm{CI}]$ & $p$ value & Odds ratio per SD $[95 \% \mathrm{CI}]$ & $P$ value & Odds ratio per SD $[95 \% \mathrm{CI}]$ & $p$ value \\
\hline \multicolumn{8}{|c|}{ Estimates for incident atrial fibrillation } \\
\hline MR-proANP & 3386 & $3.31[2.31 ; 4.81]$ & $<0.0001$ & $3.19[2.22 ; 4.65]$ & $<0.0001$ & $2.82[1.86 ; 4.35]$ & $<0.0001$ \\
\hline \multicolumn{8}{|c|}{$\begin{array}{l}\text { Estimates for incident cardiovascular disease (comprising atrial fibrillation, coronary artery disease, myocardial infarction, heart failure, or } \\
\text { stroke) }\end{array}$} \\
\hline MR-proANP & 3015 & $1.33[1.04 ; 1.71]$ & 0.025 & $1.33[1.03 ; 1.71]$ & 0.026 & $1.49[1.13 ; 1.96]$ & 0.0046 \\
\hline
\end{tabular}

Statistically significant $p$ values (i.e. $<0.05$ ) are given in bold font

Odds ratios and $95 \%$ confidence intervals are derived from a logistic regression model modeling for incident atrial fibrillation or cardiovascular disease (dependent variables) per 1-standard deviation increase in MR-proANP levels (independent variable). There were 43 incident cases of atrial fibrillation and 103 incident cases of cardiovascular disease at follow-up. $n$ denotes model 3

Model 1 was adjusted for sex (categorical) and age (continuous)

Model 2 was additionally adjusted for socioeconomic status (continuous), length of time at current residence (continuous), and night shift work (categorical)

Model 3 was additionally adjusted for diabetes mellitus, arterial hypertension, smoking, obesity, dyslipidemia, family history of myocardial infarction or stroke, and medication use (diabetic drugs, antithrombotic agents, antihypertensives, diuretics, beta-blockers, calcium channel blocker, agents acting on the renin-angiotensin-aldosterone system, and lipid modifying agents) (all categorical)

Table 4 Association between levels of MR-proANP and all-cause mortality

\begin{tabular}{|c|c|c|c|c|c|c|}
\hline \multirow[t]{2}{*}{$n$} & \multicolumn{2}{|l|}{ Model 1} & \multicolumn{2}{|l|}{ Model 2} & \multicolumn{2}{|l|}{ Model 3} \\
\hline & $\begin{array}{l}\text { Hazard ratio per SD }[95 \% \\
\mathrm{CI}]\end{array}$ & $p$ value & $\begin{array}{l}\text { Hazard ratio per SD }[95 \% \\
\mathrm{CI}]\end{array}$ & $p$ value & $\begin{array}{l}\text { Hazard ratio per SD }[95 \% \\
\mathrm{CI}]\end{array}$ & $p$ value \\
\hline
\end{tabular}

Estimates for all-cause mortality

MR-proANP $48301.41[1.26 ; 1.58] \quad \quad<\mathbf{0 . 0 0 0 1} 1.42[1.27 ; 1.60]$

$<\mathbf{0 . 0 0 0 1} 1.36[1.19 ; 1.55]$

$<0.0001$

Statistically significant $p$ values (i.e. $<0.05$ ) are given in bold font

Hazard ratios and 95\% confidence intervals are derived from a Cox proportional hazard regression model modeling for all-cause mortality (dependent variable) per 1-standard deviation increase in MR-proANP levels (independent variable). There were 301 deaths at follow-up. $n$ denotes model 3

Model 1 was adjusted for sex (categorical) and age (continuous)

Model 2 was additionally adjusted for socioeconomic status (continuous), length of time at current residence (continuous), and night shift work (categorical)

Model 3 was additionally adjusted for diabetes mellitus, arterial hypertension, smoking, obesity, dyslipidemia, family history of myocardial infarction or stroke, and medication use (diabetic drugs, antithrombotic agents, antihypertensives, diuretics, beta-blockers, calcium channel blocker, agents acting on the renin-angiotensin-aldosterone system, and lipid modifying agents) (all categorical)

sleep disturbances and annoyance reactions [23]. Annoyance by chronic low-level noise exposure and its interference with daily activities and sleep can lead to increased stress hormone levels (e.g. cortisol and noradrenaline), blood pressure, and heart rate via activation of the hypothalamus-pituitary-adrenal axis or the sympathetic nervous system, which in turn favors the development and acceleration of cardiovascular risk factors and diseases [2, 7, 24]. Besides this, chronic noise exposure and related annoyance are also associated with mental disorders such as depression and anxiety, cognitive dysfunction, and maladaptive coping mechanisms in the manner of lifestyle risk factors such as physical inactivity, smoking, and alcohol consumption that may contribute to increased risk of cardiovascular disease $[8,25]$.
In this subsample of the GHS, noise annoyance was a major environmental problem with an epidemic character, affecting almost $80 \%$ of the participants. In particular, aircraft noise was the leading source of annoyance, affecting the most participants during day and sleep, which is in line with previous results of the GHS [13, 26]. In the present study, aircraft noise was the only source of annoyance that was associated with increased levels of MR-proANP during the day as well as during sleep, while aircraft noise annoyance during sleep had an even stronger impact on MR-proANP levels than during the day. In general, effect estimates were higher during nighttime than during daytime, which goes along with previous (pre)clinical studies indicating that in particular nighttime aircraft noise induces adverse cardiovascular effects, including increased stress hormone 
release, elevated blood pressure, endothelial dysfunction, and increased arterial stiffness $[9,10,27,28]$. This may reflect the adverse effect of nighttime noise on sleep quality and its importance for cardiovascular health [29].

\section{Midregional pro atrial natriuretic peptide as a biomarker for increased risk in the context of noise annoyance}

The natriuretic peptide MR-proANP is a cardiac hormone released by the atrium, which effectively controls blood pressure and plasma volume through inhibition of the renin-angiotensin-aldosterone system and catecholamine release and stimulation of natriuresis and vasodilation in response to wall stretch [30]. Its role for cardiovascular prognosis is well-established, showing that its assessment is useful in several cardiovascular disease phenotypes including chronic and acute heart failure, atrial fibrillation, hypertension, acute myocardial infarction, and stroke [15, 31]. Likewise, MR-proANP has been shown e.g. to improve prediction of mortality in patients with ST-segment elevation myocardial infarction [32] and to represent one of the strongest predictors of cardiovascular outcome in stable angina [33].

Further, MR-proANP has been directly correlated with endothelial dysfunction obtained by various noninvasive vascular function testing methodologies [14, 34]. Endothelial dysfunction is regarded as an early key event in the development of manifest cardiovascular disease with studies indicating its predictive role for the future development of cardiovascular events and mortality risk [35]. Indeed, experimental animal and human studies have shown that traffic noise-induced autonomic perturbation and sympathoadrenal activation lead to increased levels of circulating stress hormones and oxidative stress-induced endothelial dysfunction accompanied by the release of proinflammatory mediators, increased oxidative stress $[9,10,24,28]$, and activation of prothrombotic pathways [12]. Thus, MRproANP may reflect a compensatory mechanism to reduce the cardiovascular load in response to increased noise stress. Of note, since noise annoyance also reflects mental stress and has been associated with psychological disorders, it is important to mention that growing evidence suggests that MR-proANP play a role in the neurobiology of affective disorders modulating emotional and endocrine stress responses $[26,36]$. In addition, recent studies have shown that chronic exposure to transportation noise caused by aircraft and road traffic noise is associated with higher amygdala activity, a limbic structure that is involved in stress perception, leading to vascular inflammation and increased cardiovascular event rates [37, 38]. In support of this, MR-proANP was recently shown to predict impaired physical and mental quality of life [39]. Consistent with the above-mentioned results,
MR-proANP was a strong predictor of death as well as incident atrial fibrillation and cardiovascular events further comprising coronary artery disease, myocardial infarction, heart failure, and stroke. Thus, these findings may provide mechanistic insight by which environmental noise induces adverse cardiovascular effects.

\section{Strengths and limitations}

Strengths of the present study include the novelty of examining the association between noise annoyance and levels of MR-proANP in a large population-representative sample. The comprehensive and highly standardized assessment of sociodemographic variables, cardiovascular risk factors, biomarkers, and medication use enabled to adjust for a broad spectrum of confounders. Also, the assessment of various sources of noise annoyance during day and sleep is notable. Some limitations, however, need to be considered. The observational, partly cross-sectional nature of the study does not allow for causal inferences and residual confounding cannot be fully excluded. As no data were available on objective noise levels, we considered annoyance to be a valid indicator of adverse noise-induced effects. This may increase risk of misclassification. Furthermore, we cannot exclude that air pollution (annoyance) may have affected the present results, although studies support the concept that both noise and air pollution independently affect health [40, 41]. Lastly, we cannot evaluate how specific sources of noise annoyance may have interacted or influenced each other.

\section{Conclusions}

Environmental noise-induced annoyance, in particular by nighttime aircraft noise exposure, is a major health problem, affecting large parts of the population. This is the first study showing that noise annoyance is associated with increased levels of MR-proANP being a biomarker for the increased risk of incident cardiovascular events and death, providing further mechanistic insight to explain and support the increased cardiovascular risk observed in epidemiological noise studies. These results may contribute to a better understanding of pathophysiological mechanisms involved in the noise-annoyance-disease relationship, allowing to develop specific (pharmacological) interventions and preventive measures. Environmental noise exposure should be regarded as a manifest cardiovascular risk factor, which can hardly be modified by patients or physicians but rather by politicians and legislators, introducing noise limits that reduce the adverse cardiovascular effects of noise. Therefore, measures such as inclusion into the new European Society of Cardiology guidelines for cardiovascular prevention [42] should be implemented. 
Acknowledgements Open Access funding provided by Projekt DEAL. We appreciate the contribution of the participants of the GHS as well as the excellent assistance of all technicians, study nurses, and co-workers involved in the GHS.

Author contribution $\mathrm{OH}$ and TM are the guarantors of this work and, as such, had full access to all the data in the study and take responsibility for the integrity of the data and the accuracy of the data analysis.

Funding The GHS is funded through the government of RhinelandPalatinate ("Stiftung Rheinland-Pfalz für Innovation", contract AZ 961-386261/733), the research programs "Wissen schafft Zukunft" and "Center for Translational Vascular Biology (CTVB)" of the Johannes Gutenberg-University of Mainz, and its contract with Boehringer Ingelheim and PHILIPS Medical Systems, including an unrestricted grant for the GHS and by the Foundation Heart of Mainz. The funders had no role in study design, data collection and analysis, decision to publish, or preparation of the manuscript.

\section{Compliance with ethical standards}

Conflict of interest T.M. and P.S.W. are PI's of the DZHK, Partner Site Rhine-Main, Mainz, Germany. P.S.W. and J.H.P. are funded by the Federal Ministry of Education and Research (BMBF 01EO1503). The remaining authors declare no competing financial interests.

Open Access This article is licensed under a Creative Commons Attribution 4.0 International License, which permits use, sharing, adaptation, distribution and reproduction in any medium or format, as long as you give appropriate credit to the original author(s) and the source, provide a link to the Creative Commons licence, and indicate if changes were made. The images or other third party material in this article are included in the article's Creative Commons licence, unless indicated otherwise in a credit line to the material. If material is not included in the article's Creative Commons licence and your intended use is not permitted by statutory regulation or exceeds the permitted use, you will need to obtain permission directly from the copyright holder. To view a copy of this licence, visit http://creativecommons.org/licenses/by/4.0/.

\section{References}

1. Kempen EV, Casas M, Pershagen G, Foraster M (2018) WHO Environmental noise guidelines for the European region: a systematic review on environmental noise and cardiovascular and metabolic effects: a summary. Int J Environ Res Public Health. https://doi.org/10.3390/ijerph15020379

2. Munzel T, Schmidt FP, Steven S, Herzog J, Daiber A, Sorensen M (2018) Environmental noise and the cardiovascular system. J Am Coll Cardiol 71(6):688-697. https://doi.org/10.1016/j. jacc.2017.12.015

3. Hahad O, Kroller-Schon S, Daiber A, Munzel T (2019) The cardiovascular effects of noise. Dtsch Arztebl Int 116(14):245-250. https://doi.org/10.3238/arztebl.2019.0245

4. Babisch W (2002) The noise/stress concept, risk assessment and research needs. Noise Health 4(16):1-11

5. Babisch W (2003) Stress hormones in the research on cardiovascular effects of noise. Noise Health 5(18):1-11

6. Munzel T, Gori T, Babisch W, Basner M (2014) Cardiovascular effects of environmental noise exposure. Eur Heart J 35(13):829836. https://doi.org/10.1093/eurheartj/ehu030

7. Daiber A, Kroller-Schon S, Frenis K, Oelze M, Kalinovic S, Vujacic-Mirski K, Kuntic M, Bayo Jimenez MT, Helmstadter J,
Steven S, Korac B, Munzel T (2019) Environmental noise induces the release of stress hormones and inflammatory signaling molecules leading to oxidative stress and vascular dysfunction-Signatures of the internal exposome. BioFactors 45(4):495-506. https ://doi.org/10.1002/biof.1506

8. Hahad O, Prochaska JH, Daiber A, Muenzel T (2019) Environmental noise-induced effects on stress hormones, oxidative stress, and vascular dysfunction: key factors in the relationship between cerebrocardiovascular and psychological disorders. Oxid Med Cell Longev 2019:4623109. https://doi.org/10.1155/2019/46231 09

9. Schmidt FP, Basner M, Kroger G, Weck S, Schnorbus B, Muttray A, Sariyar M, Binder H, Gori T, Warnholtz A, Munzel T (3514a) Effect of nighttime aircraft noise exposure on endothelial function and stress hormone release in healthy adults. Eur Heart J 34(45):3508-3514a. https://doi.org/10.1093/eurheartj/eht269

10. Schmidt F, Kolle K, Kreuder K, Schnorbus B, Wild P, Hechtner M, Binder H, Gori T, Munzel T (2015) Nighttime aircraft noise impairs endothelial function and increases blood pressure in patients with or at high risk for coronary artery disease. Clin Res Cardiol 104(1):23-30. https://doi.org/10.1007/s00392-014-0751-x

11. Foraster M, Eze IC, Schaffner E, Vienneau D, Heritier H, Endes S, Rudzik F, Thiesse L, Pieren R, Schindler C, Schmidt-Trucksass A, Brink M, Cajochen C, Marc Wunderli J, Roosli M, ProbstHensch N (2017) Exposure to road, railway, and aircraft noise and arterial stiffness in the sapaldia study: annual average noise levels and temporal noise characteristics. Environ Health Perspect 125(9):097004. https://doi.org/10.1289/EHP1136

12. Herzog J, Schmidt FP, Hahad O, Mahmoudpour SH, Mangold AK, Garcia Andreo P, Prochaska J, Koeck T, Wild PS, Sorensen M, Daiber A, Munzel T (2019) Acute exposure to nocturnal train noise induces endothelial dysfunction and pro-thromboinflammatory changes of the plasma proteome in healthy subjects. Basic Res Cardiol 114(6):46. https://doi.org/10.1007/s0039 5-019-0753-y

13. Hahad O, Beutel M, Gori T, Schulz A, Blettner M, Pfeiffer N, Rostock T, Lackner K, Sorensen M, Prochaska JH, Wild PS, Munzel T (2018) Annoyance to different noise sources is associated with atrial fibrillation in the Gutenberg health study. Int J Cardiol 264:79-84. https://doi.org/10.1016/j.ijcard.2018.03.126

14. Schnabel RB, Wild PS, Schulz A, Zeller T, Sinning CR, Wilde S, Kunde J, Lubos E, Lackner KJ, Warnholtz A, Gori T, Blankenberg S, Munzel T, Gutenberg Health Study I (2012) Multiple endothelial biomarkers and noninvasive vascular function in the general population: the Gutenberg Health Study. Hypertension 60(2):288-295. https://doi.org/10.1161/HYPERTENSIONAHA .112 .191874

15. Idzikowska K, Zielinska M (2018) Midregional pro-atrial natriuretic peptide, an important member of the natriuretic peptide family: potential role in diagnosis and prognosis of cardiovascular disease. J Int Med Res 46(8):3017-3029. https://doi. org/10.1177/0300060518786907

16. Wild PS, Zeller T, Beutel M, Blettner M, Dugi KA, Lackner KJ, Pfeiffer N, Munzel T, Blankenberg S (2012) The Gutenberg Health Study. Bundesgesundheitsblatt Gesundheitsforschung Gesundheitsschutz 55(6-7):824-829. https://doi.org/10.1007/ s00103-012-1502-7

17. Felscher-Suhr U, Guski R, Schuemer R (2000) Internationale Standardisierungsbestrebungen zur Erhebung von Lärmbelästigung. Zeitschrift für Lärmbekämpfung 47:68-70

18. World Health Organization (2000) Obesity: preventing and managing the global epidemic. https://www.who.int/nutrition/publi cations/obesity/WHO_TRS_894/en/. Accessed 16 Apr 2020

19. Obesity: preventing and managing the global epidemic. Report of a WHO consultation (2000). World Health Organ Tech Rep Ser 894:i-xii, 1-253 
20. Lampert T, Kroll LE, Muters S, Stolzenberg H (2013) Measurement of the socioeconomic status within the German Health Update 2009 (GEDA). Bundesgesundheitsblatt Gesundheitsforschung Gesundheitsschutz 56(1):131-143. https://doi. org/10.1007/s00103-012-1583-3

21. Munzel T, Hahad O, Gori T, Hollmann S, Arnold N, Prochaska JH, Schulz A, Beutel M, Pfeiffer N, Schmidtmann I, Lackner KJ, Keaney JF Jr, Wild PS (2019) Heart rate, mortality, and the relation with clinical and subclinical cardiovascular diseases: results from the Gutenberg Health Study. Clin Res Cardiol 108(12):13131323. https://doi.org/10.1007/s00392-019-01466-2

22. Panova-Noeva M, Neu MA, Eckerle S, Spix C, Schneider A, Schmidtmann I, Spronk HM, Pfeiffer N, Beutel M, Lackner KJ, Munzel T, Ten Cate H, Merzenich H, Faber J, Wild PS (2019) Cardiovascular risk factors are important determinants of plateletdependent thrombin generation in adult survivors of childhood cancer. Clin Res Cardiol 108(4):438-447. https://doi.org/10.1007/ s00392-018-1374-4

23. World Health Organization (2011) Burden of disease from environmental noise.http://www.euro.who.int/__data/assets/pdf_ file/0008/136466/e94888.pdf. Accessed 16 Apr 2020

24. Munzel T, Sorensen M, Gori T, Schmidt FP, Rao X, Brook FR, Chen LC, Brook RD, Rajagopalan S (2017) Environmental stressors and cardio-metabolic disease: part II-mechanistic insights. Eur Heart J 38(8):557-564. https://doi.org/10.1093/eurheartj/ehw294

25. Fang XY, Spieler D, Albarqouni L, Ronel J, Ladwig KH (2018) Impact of generalized anxiety disorder (GAD) on prehospital delay of acute myocardial infarction patients. Findings from the multicenter MEDEA study. Clin Res Cardiol 107(6):471-478. https://doi.org/10.1007/s00392-018-1208-4

26. Beutel ME, Junger C, Klein EM, Wild P, Lackner K, Blettner M, Binder H, Michal M, Wiltink J, Brahler E, Munzel T (2016) Noise annoyance is associated with depression and anxiety in the general population - the contribution of aircraft noise. PLoS ONE 11(5):e0155357. https://doi.org/10.1371/journal.pone.0155357

27. Munzel T, Daiber A, Steven S, Tran LP, Ullmann E, Kossmann S, Schmidt FP, Oelze M, Xia N, Li H, Pinto A, Wild P, Pies K, Schmidt ER, Rapp S, Kroller-Schon S (2017) Effects of noise on vascular function, oxidative stress, and inflammation: mechanistic insight from studies in mice. Eur Heart J 38(37):2838-2849. https ://doi.org/10.1093/eurheartj/ehx081

28. Kroller-Schon S, Daiber A, Steven S, Oelze M, Frenis K, Kalinovic S, Heimann A, Schmidt FP, Pinto A, Kvandova M, Vujacic-Mirski K, Filippou K, Dudek M, Bosmann M, Klein M, Bopp T, Hahad O, Wild PS, Frauenknecht K, Methner A, Schmidt ER, Rapp S, Mollnau H, Munzel T (2018) Crucial role for Nox2 and sleep deprivation in aircraft noise-induced vascular and cerebral oxidative stress, inflammation, and gene regulation. Eur Heart J 39(38):3528-3539. https://doi.org/10.1093/eurheartj/ehy333

29. Basner M, McGuire S (2018) WHO environmental noise guidelines for the European region: a systematic review on environmental noise and effects on sleep. Int J Environ Res Public Health. https://doi.org/10.3390/ijerph15030519

30. Khaleghi M, Saleem U, Morgenthaler NG, Turner ST, Bergmann A, Struck J, Mosley TH, Kullo IJ (2009) Plasma midregional proatrial natriuretic peptide is associated with blood pressure indices and hypertension severity in adults with hypertension. Am J Hypertens 22(4):425-431. https://doi.org/10.1038/ajh.2009.8

31. Sepehri Shamloo A, Bollmann A, Dagres N, Hindricks G, Arya A (2020) Natriuretic peptides: biomarkers for atrial fibrillation management. Clin Res Cardiol. https://doi.org/10.1007/s0039 2-020-01608-x

32. Lindberg S, Jensen JS, Pedersen SH, Galatius S, Goetze JP, Mogelvang R (2015) MR-proANP improves prediction of mortality and cardiovascular events in patients with STEMI. Eur J
Prev Cardiol 22(6):693-700. https://doi.org/10.1177/2047487314 538856

33. Schnabel RB, Schulz A, Messow CM, Lubos E, Wild PS, Zeller T, Sinning CR, Rupprecht HJ, Bickel C, Peetz D, Cambien F, Kempf T, Wollert KC, Benjamin EJ, Lackner KJ, Munzel TF, Tiret L, Vasan RS, Blankenberg S (2010) Multiple marker approach to risk stratification in patients with stable coronary artery disease. Eur Heart J 31(24):3024-3031. https://doi.org/10.1093/eurheartj/ ehq322

34. Kathiresan S, Gona P, Larson MG, Vita JA, Mitchell GF, Tofler GH, Levy D, Newton-Cheh C, Wang TJ, Benjamin EJ, Vasan RS (2006) Cross-sectional relations of multiple biomarkers from distinct biological pathways to brachial artery endothelial function. Circulation 113(7):938-945. https://doi.org/10.1161/CIRCU LATIONAHA.105.580233

35. Daiber A, Steven S, Weber A, Shuvaev VV, Muzykantov VR, Laher I, Li H, Lamas S, Munzel T (2017) Targeting vascular (endothelial) dysfunction. Br J Pharmacol 174(12):1591-1619. https://doi.org/10.1111/bph.13517

36. Meyer T, Herrrmann-Lingen C, Chavanon ML, Nolte K, Pasedach CA, Binder L, Pieske B, Hasenfuss G, Wachter R, Edelmann F (2015) Higher plasma levels of MR-pro-atrial natriuretic peptide are linked to less anxiety: results from the observational DIAST-CHF study. Clin Res Cardiol 104(7):574-581. https://doi. org/10.1007/s00392-015-0820-9

37. Osborne MT, Radfar A, Hassan MZO, Abohashem S, Oberfeld B, Patrich T, Tung B, Wang Y, Ishai A, Scott JA, Shin LM, Fayad ZA, Koenen KC, Rajagopalan S, Pitman RK, Tawakol A (2019) A neurobiological mechanism linking transportation noise to cardiovascular disease in humans. Eur Heart J. https://doi.org/10.1093/ eurheartj/ehz820

38. Munzel T, Steven S, Hahad O, Daiber A (2019) The sixth sense is involved in noise-induced stress responses and vascular inflammation: evidence for heightened amygdalar activity in response to transport noise in man. Eur Heart J. https://doi.org/10.1093/eurhe artj/ehz867

39. Zelenak C, Chavanon ML, Tahirovic E, Trippel TD, Tscholl V, Stroux A, Veskovic J, Apostolovic S, Obradovic D, Zdravkovic M, Loncar G, Stork S, Herrmann-Lingen C, Dungen HD (2019) Early NT-proBNP and MR-proANP associated with QoL 1 year after acutely decompensated heart failure: secondary analysis from the MOLITOR trial. Biomark Med 13(17):1493-1507. https:// doi.org/10.2217/bmm-2019-0083

40. Munzel T, Sorensen M, Gori T, Schmidt FP, Rao X, Brook J, Chen LC, Brook RD, Rajagopalan S (2017) Environmental stressors and cardio-metabolic disease: part I-epidemiologic evidence supporting a role for noise and air pollution and effects of mitigation strategies. Eur Heart J 38(8):550-556. https://doi.org/10.1093/ eurheartj/ehw269

41. Stansfeld SA (2015) Noise effects on health in the context of air pollution exposure. Int J Environ Res Public Health 12(10):12735-12760. https://doi.org/10.3390/ijerph121012735

42. Piepoli MF, Hoes AW, Agewall S, Albus C, Brotons C, Catapano AL, Cooney MT, Corra U, Cosyns B, Deaton C, Graham I, Hall MS, Hobbs FDR, Lochen ML, Lollgen H, Marques-Vidal P, Perk J, Prescott E, Redon J, Richter DJ, Sattar N, Smulders Y, Tiberi M, van der Worp HB, van Dis I, Verschuren WMM, Binno S, Group ESCSD (2016) European Guidelines on cardiovascular disease prevention in clinical practice: the sixth joint task force of the european society of cardiology and other societies on cardiovascular disease prevention in clinical practice (constituted by representatives of 10 societies and by invited experts) developed with the special contribution of the European Association for Cardiovascular Prevention and Rehabilitation (EACPR). Eur Heart J 37(29):2315-2381. https://doi.org/10.1093/eurheartj/ehw106 